\title{
Correction: Induction of labour with a Foley catheter or oral misoprostol at term: the PROBAAT-II study, a multicentre randomised controlled trial
}

\author{
Mieke LG ten Eikelder ${ }^{1}$, Femke Neervoort ${ }^{2}$, Katrien Oude Rengerink ${ }^{3}$, Gert J van Baaren ${ }^{3}$, Marta Jozwiak ${ }^{1}$, \\ Jan-Willem de Leeuw ${ }^{4}$, Irene de Graaf ${ }^{3}$, Maria G van Pampus ${ }^{2}$, Maureen Franssen ${ }^{5}$, Martijn Oudijk ${ }^{7}$, \\ Paulien van der Salm ${ }^{7}$, Mallory Woiski ${ }^{6}$, Paula JM Pernet ${ }^{8}$, A Hanneke Feitsma ${ }^{9}$, Huib van Vliet ${ }^{10}$, Martina Porath ${ }^{11}$, \\ Frans Roumen ${ }^{12}$, Erik van Beek ${ }^{13}$, Hans Versendaal ${ }^{14}$, Marion Heres $^{15}$, Ben Willem J Mol ${ }^{3}$ and \\ Kitty WM Bloemenkamp ${ }^{1 *}$
}

Additional author: During the editing process of the article "Induction of labour with a Foley catheter or oral misoprostol at term: the PROBAAT-II study, a multicentre randomised controlled trial“ [1] an author has been accidentally removed from the author list. Gert J van Baaren (Department of Obstetrics and Gynecology, Academic Medical Centre, Amsterdam, the Netherlands, g.j.vanbaaren@amc.uva.nl) critically revised the first draft, and approved the final version of the manuscript. He was especially involved in the sections relating to the cost-effectiveness analysis.

\section{Author details}

'Department of Obstetrics K-6-P-35, LLeiden University Medical Centre, P.O. Box 9600, Leiden 2300 RC, the Netherlands. ${ }^{2}$ Department of Obstetrics and Gynaecology, Onze Lieve Vrouwe Gasthuis, Amsterdam, the Netherlands. ${ }^{3}$ Department of Obstetrics and Gynaecology, Academic Medical Centre, Amsterdam, the Netherlands. ${ }^{4}$ Department of Obstetrics and Gynaecology, Ikazia Hospital, Rotterdam, the Netherlands. ${ }^{5}$ Department of Obstetrics and Gynaecology, University Medical Centre Groningen, Groningen, the Netherlands. ${ }^{6}$ Department of Obstetrics and Gynaecology, Radboud University, Nijmegen, the Netherlands. ${ }^{7}$ Department of Obstetrics and Gynaecology, University Medical Centre Utrecht, Utrecht, the Netherlands. ${ }^{8}$ Department of Obstetrics and Gynaecology, Kennemer Gasthuis, Haarlem, the Netherlands. ${ }^{9}$ Department of Obstetrics and Gynaecology, HAGA Hospital, Den Haag, the Netherlands. ${ }^{10}$ Department of Obstetrics and Gynaecology, Catharina Hospital, Eindhoven, the Netherlands. ${ }^{11}$ Department of Obstetrics and Gynaecology, Maxima Medical Centre, Veldhoven, the Netherlands. ${ }^{12}$ Department of Obstetrics and Gynaecology, Atrium Medical Centre, Heerlen, the Netherlands. ${ }^{13}$ Department of Obstetrics and Gynaecology, Sint Antonius Hospital, Nieuwegein, the Netherlands.

\footnotetext{
* Correspondence: K.W.M.Bloemenkamp@lumc.nl

'Department of Obstetrics K-6-P-35, LLeiden University Medical Centre, P.O. Box 9600, Leiden 2300 RC, the Netherlands

Full list of author information is available at the end of the article
}

${ }^{14}$ Department of Obstetrics and Gynaecology, Maasstad Hospital, Rotterdam the Netherlands. ${ }^{15}$ Department of Obstetrics and Gynaecology, Sint Lucas Andreas Hospital, Amsterdam, the Netherlands.

Received: 9 October 2013 Accepted: 9 October 2013

Published: 31 October 2013

\section{Reference}

1. ten Eikelder MLG, Femke N, Katrien Oude R, Marta J, de Leeuw J-W, de Graaf I, van Pampus MG, Maureen F, Martijn O, van der Salm P, Mallory W, Paula JM P. Hanneke Feitsma A, van Vliet H, Martina P, Frans R, van Beek E, Hans V, Marion H, Mol BWJ, Bloemenkamp KWM: Induction of labour with a Foley catheter or oral misoprostol at term: the PROBAAT-II study, a multicentre randomised controlled trial. BMC Pregnancy and Childbirth 2013, 13:67.

doi:10.1186/1471-2393-13-183

Cite this article as: ten Eikelder et al:: Correction: Induction of labour with a Foley catheter or oral misoprostol at term: the PROBAAT-II study, a multicentre randomised controlled trial. BMC Pregnancy and Childbirth 2013 13:183

\section{Submit your next manuscript to BioMed Central} and take full advantage of:

- Convenient online submission

- Thorough peer review

- No space constraints or color figure charges

- Immediate publication on acceptance

- Inclusion in PubMed, CAS, Scopus and Google Scholar

- Research which is freely available for redistribution 